\title{
An investigation of barriers to the use of the World Health Organization Surgical Safety Checklist in theatres
}

\author{
S Verwey, MB ChB, DA (SA), FCA (SA); P D Gopalan, MB ChB, DA (SA), FCA (SA), Crit Care (Anaesthetics) \\ Department of Anaesthesiology and Critical Care, Nelson R Mandela School of Medicine, College of Health Sciences, University of KwaZulu-Natal, \\ Durban, South Africa
}

Corresponding author: S Verwey (stefneventer@hotmail.com)

Background. The World Health Organization (WHO) has implemented the Surgical Safety Checklist (SSCL) as part of the Safe Surgery Saves Lives campaign. This is aimed at improving surgical safety worldwide. Despite many perceived benefits of the SSCL, compliance and acceptance in many areas remain poor.

Objectives. To investigate perceptions of theatre staff regarding the checklist and to identify reasons and barriers for poor compliance and implementation.

Methods. Questionnaires were handed out to theatre teams across all surgical disciplines at two large hospitals in Durban, South Africa, over a 2-week period. Data collected included role in theatre, intention of the SSCL, training received, as well as questions regarding previously identified barriers and staff perceptions.

Results. Questionnaires were distributed to 225 practitioners, with a response rate of $81.7 \%$ from 51 nurses, 54 anaesthetists and 79 surgeons. Rank of medical staff included 52 seniors (consultants) and 81 juniors (registrars and medical officers). The majority (95\%) of respondents perceived the SSCL as intended to improve safety, prevent errors or reduce morbidity and mortality. A total of 146 respondents (79.3\%) received no SSCL training. No new barriers were identified, but previously identified barriers were confirmed. Our key factors were time-related issues and lack of buy-in from team members. Surgeons were perceived as being supportive by $45.1 \%$ of respondents, in contrast to nurses $(62.5 \%)$, anaesthetists $(70.1 \%)$ and management $(68.5 \%)$. When compared with junior staff, senior staff were 5 -fold more likely to feel that staff did not need to be trained and 8-fold more likely to indicate that the checklist did not improve patient safety. Conclusions. The WHO SSCL is an important tool in the operating room environment. The barriers in our setting are similar to those identified in other settings. There needs to be widespread training in the use of the SSCL, including adaptation of the checklist to make it fit for purpose in our setting. Improving use of the checklist will allow theatre staff to work together towards ensuring a safer theatre environment for both patients and staff.

S Afr Med J 2018;108(4):336-341. DOI:10.7196/SAMJ.2018.v108i4.12780

Surgical procedures are an essential part of modern medicine. It is estimated that there are 187.2 - 281.2 million major surgical cases per year, equating to about one procedure per 25 people. ${ }^{[1]}$ Surgery, however, is not without risk. An Australian study that investigated negative events associated with surgery found that $21.9 \%$ of surgical admissions were associated with an adverse event, and that $47.6 \%$ of these were preventable complications. ${ }^{[2]}$ In more recent studies, the International Surgical Outcomes Study (ISOS) showed that $16.8 \%$ of patients developed complications, with a mortality rate of $2.8 \%,{ }^{[3]}$ the European Surgical Outcomes Study (EuSOS) showed a mortality of $4 \%,{ }^{[4]}$ and in the South African Surgical Outcomes Study (SASOS) the mortality was 3.1\%, with the highest hospital mortality being $9.5 \%{ }^{[5]}$ Efforts to decrease adverse events and improve patient safety led to the Safe Surgery Saves Lives programme and subsequently to the World Health Organization Surgical Safety Checklist (WHO SSCL). ${ }^{[6]}$

The WHO SSCL was introduced in 2008 and is aimed at improving patient safety and inter-discipline communication and preventing avoidable complications by emphasising current safety procedures. It comprises a list of questions asked at three intervals during the procedure: before induction of anaesthesia, prior to skin incision and before the patient leaves the operating theatre. ${ }^{[6]}$

A pilot study done after introduction of the WHO SSCL to assess the effect of implementation showed a reduction in surgical complication rate, surgical site infection, unexpected re-operation and death rate in hospital. ${ }^{[7]}$ Another study, showing improvement of patient identification and surgical site confirmation, emphasised that better understanding of each team member's role aided in better communication and teamwork. ${ }^{[8]}$

Other studies have shown contradictory results. Urbach et al. ${ }^{[9]}$ investigated the effect of surgical safety checklists at 101 hospitals. They compared mortality data, surgical complications and readmissions before and after implementation of an SSCL, which did not show any significant differences. Lübbeke et al ${ }^{[10]}$ also showed no effect on 30-day mortality, unplanned critical care admissions and unplanned repeat surgery.

In the SA setting, a recent study investigated the use of a modified SSCL and its impact on maternal outcomes. ${ }^{[1]}$ In centres where the checklist was implemented, there was a significant reduction in complications, such as postoperative infections (from 10 to 6.2 events per 1000 procedures) and unplanned repeat surgery (from 9.6 to 6.9 events per 1000 procedures). In centres that were regarded as 'good implementers' (based on the level of implementation), there was a significant improvement in incident rate ratios for combined outcomes $(p=0.001)$ and maternal mortality $(p=0.023)$.

Nonetheless, the SSCL is still poorly and incorrectly implemented at many hospitals. In a study by Naidoo et al., ${ }^{[11]}$ the SSCL was implemented at 9 hospitals, but poorly implemented at 6 of these. In the SASOS study, the SSCL was used in $63.7 \%$ of cases (Prof. B Biccard - personal communication, 2015). 
In a study observing the completion of the SSCL, completion of parts of the checklist occurred in only $27 \%$ of cases. ${ }^{[12]}$ Levy et al. ${ }^{\left[{ }^{[13]}\right.}$ who investigated completion of the first part of the SSCL, found that only two checkpoints were completed $>90 \%$ of the time, whereas the rest of the checkpoints were completed in $<60 \%$ of cases. ${ }^{[13]}$ In Pakistan, initial checklist compliance was $20.4 \%$, which increased to $89.9 \%$ after 4 years. ${ }^{[14]}$ Bashford et al. ${ }^{[15]}$ showed a decline in the compliance rate - from $83 \%$ one month after implementation to $18 \%$ eight months after implementation.

Barriers to the effective implementation of the SSCL, as identified by Fourcade et al. ${ }^{[16]}$ include the duplication of checklist items with checks already in place, poor communication between team members, perception of the checklist as a time-consuming process without the addition of benefit to patient care and safety, poor timing for completion of the list, worsening of patient anxiety, uncertainty about each member's role, inappropriate nature of the set questions for different centres, and 'gaming', where items not checked are marked off as checked.

Naidoo et al.$^{[11]}$ identified some of these barriers. 'Poor teamwork between doctors and nurses', 'lack of support from senior healthcare workers and management' and 'personal motivation' were cited as contributing to poor implementation. In the UK, unfamiliarity, embarrassment during timeout or the introduction process, hierarchical issues, timing of the checklist and duplication of checks were recognised as challenges. Treadwell et al. ${ }^{[18]}$ grouped barriers into four categories: confusion regarding the proper use of the SSCL; pragmatic changes to efficient workflow; access to resources; and individual staff beliefs and attitudes.

Our questionnaire-based study aimed to identify barriers to the use of the WHO SSCL in our setting and to investigate perceptions of the SSCL held by our various staff groups. We attempted to confirm the role of barriers identified by previous studies in different settings, as well as those specific to our setting, in the hope that such knowledge could be applied to improve the use of the SSCL, and ultimately the safety of our patients.

\section{Methods}

Questionnaires were handed out to theatre teams across all surgical disciplines at two academic teaching hospitals in the complex in Durban, SA. Each theatre team consisted of scrub nurses, and anaesthetists and surgeons at both senior (consultant) and junior (registrar and medical officer) levels. A convenience sampling model was used, selecting the two largest hospitals in the complex, with each site sampled for a week. Each site had been using the checklist for at least the preceding year. We calculated that the total sample population including all staff present during the study period would be 150 .

Data collected included the respondent's role in the theatre, their sense of the intention of the checklist, and whether any training in the use of the SSCL was received. An open-ended question was also posed to evaluate the respondent's views on what made it difficult to use the checklist. This was followed by a series of questions regarding previously identified barriers ${ }^{[16]}$ and staff perceptions, to which respondents could respond 'yes', 'no', or 'don't know'. To this we added statements evaluating the respondents' overall perception of the SSCL.

\section{Ethical approval}

The Biomedical Research Ethics Committee, University of KwaZuluNatal, granted approval for the study (ref. no. BREC: BE490/14).

\section{Statistical analysis}

All data were entered onto a data sheet. SPSS Version 24.0 (IBM
Corp., USA) was used to analyse data. Descriptive statistics were used to describe the data. Categorical variables are presented as number (\%). Pearson's $\chi^{2}$ test, Fisher's exact test and binary logistic regression, where relevant, were used to test for differences among the groups. Statistical significance was set at $p<0.05$. Where relevant, results are expressed as odds ratio (OR) with $95 \%$ confidence intervals (CIs).

\section{Results}

A total of 225 questionnaires were distributed, with 184 returned, giving a response rate of $81.7 \%$. Of the returned responses, 7 (3.8\%) respondents had not previously heard of the checklist. The distribution of the respondents with regard to their roles in theatre and their ranks are shown in Table 1.

Responses to the open-ended question regarding the intention of the WHO SSCL were grouped according to themes that emerged. These are reflected in six groups in Table 2. Some gave more than one answer, with 21 respondents included in groups 1 and 2 (Table 2). All 18 responses alluding to the avoidance of medicolegal hazards were from nursing staff.

A total of $146(79.3 \%)$ respondents indicated that they had not received any training with regard to the WHO SSCL. Of the 38 who

\begin{tabular}{ll} 
Table 1. Demographics of respondents & \\
\hline Demographics & $\boldsymbol{n}(\%)$ \\
\hline Hospital & $77(41.8)$ \\
$\quad$ Site 1 & $107(58.2)$ \\
$\quad$ Site 2 & \\
Role in theatre & $51(27.7)$ \\
$\quad$ Scrub nurse & $54(29.3)$ \\
$\quad$ Anaesthetist & $79(42.9)$ \\
$\quad$ Surgeon & \\
Rank of medical staff & $52(39.1)$ \\
$\quad$ Senior (consultants) & $81(60.9)$ \\
$\quad$ Junior (registrars and medical officers) &
\end{tabular}

Table 2. Perceptions of the intention of the WHO SSCL

\begin{tabular}{lll}
\hline Group & Responses & $\boldsymbol{n}(\%)$ \\
\hline 1 & Improving patient and surgery safety & $122(66.3)$ \\
2 & $\begin{array}{l}\text { Prevention of errors and reducing } \\
\text { morbidity and mortality }\end{array}$ & $74(40.2)$ \\
3 & Avoiding medicolegal hazards & $18(9.8)$ \\
4 & Improving communication and & $22(12.0)$ \\
& teamwork in theatre \\
5 & Improving standard of care & $2(1.1)$ \\
6 & Do not know/blank & $8(4.3)$ \\
WHO SSCL = World Health Organization Surgical Safety Checklist. &
\end{tabular}

Table 3. Factors that complicate the use of the WHO SSCL

\begin{tabular}{ll}
\hline Responses & $\boldsymbol{n}(\%)$ \\
\hline Time issues (timing and time-consuming) & $61(33.2)$ \\
Lack of buy-in from team members & $51(27.7)$ \\
Surgeons (including surgeon disinterest) & $32(17.4)$ \\
Inadequate training or lack of knowledge & $22(12.0)$ \\
Inconsistency regarding use (not routine, no policy) & $11(6.0)$ \\
Repetition & $6(3.3)$ \\
No difficulty & $34(18.5)$ \\
No response & $17(9.2)$ \\
WHO sSCL = World Health Organization Surgical Safety Checklist. &
\end{tabular}


did receive training, such training was either at another hospital, as part of their in-service training or as part of examination preparation.

Emergent factors to the open-ended question posed to explore factors complicating the use of the WHO SSCL are reflected in Table 3. The $17.4 \%$ of responses making reference to surgeons or surgeon disinterest specifically are not included in the response highlighting lack of buy-in from team members.

Table 4 reflects responses to previously identified barriers and staff perceptions of SSCL use cross-tabbed against the role of the respondents in the operating theatre, i.e. nurse, anaesthetist or surgeon. Table 5 reflects responses to the same statements crosstabbed against the rank of the medical personnel. The 'don't know' responses have been excluded from the analyses.

\section{Discussion}

Despite a worldwide drive for safer surgery, implementation of and compliance with a validated available tool, such as the WHO SSCL, remain poor. ${ }^{[9-13]}$ We aimed to identify and understand the barriers to the use of the WHO SSCL, such that recommendations could be made to enhance its use in our setting.

There was a good response rate of $81.7 \%$ to our questionnaires. The higher than anticipated number of questionnaires distributed is explained by there being more surgeons than expected. We did not attempt to differentiate between the two study sites, as the staff and practice were considered to be similar. With only $3.8 \%$ of respondents having not heard of the SSCL, and $86.4 \%$ wanting to use it, a positive platform from which to start was provided. The higher proportion of surgeons compared with anaesthetic personnel may be explained

\section{Table 4. Barriers to and staff perceptions of SSCL use in relation to role in theatre}

\begin{tabular}{|c|c|c|c|c|}
\hline Responses & $\begin{array}{l}\text { Yes, } \\
n(\%)\end{array}$ & $\begin{array}{l}\text { No, } \\
n(\%)\end{array}$ & $\begin{array}{l}\text { Significance, } \\
p \text {-value }\end{array}$ & $\begin{array}{l}\text { Odds ratio } \\
(95 \% \mathrm{CI})\end{array}$ \\
\hline The checklist takes too long to complete & $45(26.2)$ & $127(73.8)$ & & \\
\hline Anaesthetists & $12(23.1)$ & $40(76.9)$ & 0.199 & \\
\hline Nurses & $10(19.6)$ & $41(80.4)$ & & $1.230(0.478-3.166)$ \\
\hline Surgeons & $23(33.3)$ & $46(66.7)$ & & $0.600(0.265-1.358)$ \\
\hline It is difficult to find a co-ordinator for the checklist & $74(46.5)$ & $85(53.5)$ & & \\
\hline Anaesthetists & $32(61.5)$ & $20(38.5)$ & 0.013 & \\
\hline Nurses & $21(46.7)$ & $24(53.3)$ & & $1.829(0.814-4.108)$ \\
\hline Surgeons & $21(33.9)$ & $41(66.1)$ & & $3.124(1.450-6.728)$ \\
\hline I know whose responsibility it is to initiate the checklist & $79(54.1)$ & $67(45.9)$ & & \\
\hline Anaesthetists & $19(40.4)$ & $28(59.6)$ & 0.004 & \\
\hline Nurses & $30(75.0)$ & $10(25.0)$ & & $0.226(0.090-0.569)$ \\
\hline Surgeons & $30(50.8)$ & $29(49.2)$ & & $0.656(0.302-1.423)$ \\
\hline Staff needs to be trained in using the checklist & $158(89.3)$ & $19(10.7)$ & & \\
\hline Anaesthetists & $50(92.6)$ & $4(7.4)$ & 0.118 & \\
\hline Nurses & $47(94.0)$ & $3(6.0)$ & & $0.798(0.170-3.755)$ \\
\hline Surgeons & $61(83.6)$ & $12(16.4)$ & & $2.459(0.747-8.097)$ \\
\hline The checklist is a duplication of an existing check & $36(23.8)$ & $115(76.2)$ & & \\
\hline Anaesthetists & $9(19.1)$ & $38(80.9)$ & 0.174 & \\
\hline Nurses & $16(33.3)$ & $32(66.7)$ & & $0.474(0.185-1.215)$ \\
\hline Surgeons & $11(19.6)$ & $45(80.4)$ & & $0.969(0.363-2.584)$ \\
\hline It is unnecessary to use a surgical safety checklist & $22(12.6)$ & $152(87.4)$ & & \\
\hline Anaesthetists & $3(5.7)$ & $50(94.3)$ & 0.008 & \\
\hline Nurses & $12(25.0)$ & $36(75.0)$ & & $0.180(0.047-0.684)$ \\
\hline Surgeons & $7(9.6)$ & $66(90.4)$ & & $0.566(0.139-2.298)$ \\
\hline The checklist is a waste of time & $11(6.3)$ & $165(93.7)$ & & \\
\hline Anaesthetists & $2(3.8)$ & $51(96.2)$ & 0.680 & \\
\hline Nurses & $4(8.0)$ & $46(92.0)$ & & $0.451(0.079-2.578)$ \\
\hline Surgeons & $5(6.8)$ & $68(93.2)$ & & $0.533(0.099-2.860)$ \\
\hline Failing to complete the checklist is poor professional practice & $134(78.4)$ & $37(21.6)$ & & \\
\hline Anaesthetists & $45(84.9)$ & $8(15.1)$ & 0.271 & \\
\hline Nurses & $38(79.2)$ & $10(20.8)$ & & $1.480(0.531-4.126)$ \\
\hline Surgeons & $51(72.9)$ & $19(27.1)$ & & $2.096(0.837-5.249)$ \\
\hline Using the checklist decreases human error & $167(94.9)$ & $9(5.1)$ & & \\
\hline Anaesthetists & $52(96.3)$ & $2(3.7)$ & 0.754 & \\
\hline Nurses & $48(96.0)$ & $2(4.0)$ & & $1.083(0.147-7.996)$ \\
\hline Surgeons & $67(93.1)$ & $5(6.9)$ & & $1.940(0.362-10.404)$ \\
\hline Using the checklist improves patient safety & $166(96.0)$ & $7(4.0)$ & & \\
\hline Anaesthetists & $52(98.1)$ & $1(1.9)$ & 0.301 & \\
\hline Nurses & $50(98.0)$ & $1(2.0)$ & & $1.040(0.063-17.083)$ \\
\hline \multirow[t]{2}{*}{ Surgeons } & $64(92.8)$ & $5(7.2)$ & & $4.062(0.460-35.866)$ \\
\hline & & & & continue \\
\hline
\end{tabular}




\section{Table 4. (continued) Barriers to and staff perceptions of SSCL use in relation to role in theatre}

\begin{tabular}{|c|c|c|c|c|}
\hline Responses & $\begin{array}{l}\text { Yes, } \\
n(\%)\end{array}$ & $\begin{array}{l}\text { No, } \\
n(\%)\end{array}$ & $\begin{array}{l}\text { Significance, } \\
p \text {-value }\end{array}$ & $\begin{array}{l}\text { Odds ratio } \\
(95 \% \mathrm{CI})\end{array}$ \\
\hline Using the checklist improves teamwork in theatre & $146(84.9)$ & $26(15.1)$ & & \\
\hline Anaesthetists & $45(86.5)$ & $7(13.5)$ & 0.119 & \\
\hline Nurses & $46(92.0)$ & $4(8.0)$ & & $0.559(0.153-2.042)$ \\
\hline Surgeons & $55(78.6)$ & $15(21.4)$ & & $1.753(0.658-4.671)$ \\
\hline Surgical personnel support the use of the checklist & $83(56.5)$ & $64(43.5)$ & & \\
\hline Anaesthetists & $10(22.7)$ & $34(77.3)$ & 0.000 & \\
\hline Nurses & $25(55.6)$ & $20(44.4)$ & & $0.235(0.094-0.589)$ \\
\hline Surgeons & $48(82.8)$ & $10(17.2)$ & & $0.061(0.023-0.163)$ \\
\hline Anaesthetic personnel support the use of the checklist & $129(87.8)$ & $18(12.2)$ & & \\
\hline Anaesthetists & $39(84.8)$ & $7(15.2)$ & 0.163 & \\
\hline Nurses & $39(83.0)$ & $8(17.0)$ & & $1.143(0.378-3.458)$ \\
\hline Surgeons & $51(94.4)$ & $3(5.6)$ & & $0.328(0.080-1.350)$ \\
\hline Nursing personnel support the use of the checklist & $115(83.9)$ & $22(16.1)$ & & \\
\hline Anaesthetists & $26(65.0)$ & $14(35.0)$ & 0.001 & \\
\hline Nurses & $44(91.7)$ & $4(8.3)$ & & $0.169(0.050-0.568)$ \\
\hline Surgeons & $45(91.8)$ & $4(8.2)$ & & $0.165(0.049-0.554)$ \\
\hline Management support the use of the checklist & $126(90.0)$ & $14(10.0)$ & & \\
\hline Anaesthetists & $33(76.7)$ & $10(23.3)$ & 0.005 & \\
\hline Nurses & $45(95.7)$ & $2(4.3)$ & & $0.147(0.030-0.714)$ \\
\hline Surgeons & $48(96.0)$ & $2(4.0)$ & & $0.138(0.028-0.669)$ \\
\hline I want to use the checklist & $159(91.9)$ & $14(8.1)$ & & \\
\hline Anaesthetists & $51(96.2)$ & $2(3.8)$ & 0.320 & \\
\hline Nurses & $47(92.2)$ & $4(7.8)$ & & $2.170(0.380-12.402)$ \\
\hline Surgeons & $61(88.4)$ & $8(11.6)$ & & $3.344(0.680-16.457)$ \\
\hline When the checklist is used, I feel part of the team & $131(78.9)$ & $35(21.1)$ & & \\
\hline Anaesthetists & $131(78.9)$ & $35(21.1)$ & 0.001 & \\
\hline Nurses & $42(80.8)$ & $10(19.2)$ & & $0.268(0.069-1.040)$ \\
\hline Surgeons & $47(94.0)$ & $3(6.0)$ & & $2.200(0.930-5.205)$ \\
\hline
\end{tabular}

by different surgical teams on different days, with nursing and anaesthetic staff remaining more constant. The study yielded a good distribution among the different levels of medical staff.

There was an overwhelming majority of respondents (95.1\%) who perceived the SSCL as being intended to improve safety and/or prevent errors and reduce morbidity and mortality. This understanding of the intention of the SSCL by the majority makes non-compliance even more difficult to explain. All responses relating to avoidance of medicolegal hazards came from nursing personnel, indicating their increased concern about litigation. The low proportion (12\%) of respondents describing communication and teamwork in their responses is concerning. A clear majority of all respondents believed that: failing to complete the checklist was poor professional practice (72.8\%); using the checklist decreased human error (90.8\%); using the checklist improved patient safety (90.2\%); and using the checklist improved teamwork (79.3\%). Overall, it would appear that any limitation to implement the SSCL is not associated with a lack of appreciation of its intention.

No new barriers were identified during this study, as all responses to the open-ended question were related to known barriers identified in previous studies in different settings. ${ }^{[1,16,17]}$ Our key factors were time-related issues (timing and time-consuming) and a lack of buyin from team members, which were in keeping with other studies. With numerous identified factors, Treadwell et al. ${ }^{[18]}$ attempted to group barriers into the following four categories: confusion regarding the proper SSCL; pragmatic changes to efficient workflow; access to resources; and individual staff beliefs and attitudes. Factors in all four categories were identified in our cohort.

The low level of training received with regard to the SSCL in our study $(20.7 \%)$ reflects an area of concern. A Pakistani study ${ }^{[14]}$ showed a greater than 4 -fold increase in compliance over a 4-year period as training continued and momentum to SSCL use developed. Contradictorily, an Ethiopian study ${ }^{[15]}$ showed a decrease from $83 \%$ to $18 \%$ in SSCL use over 8 months after implementation, despite ongoing training. In our cohort, $12 \%$ of all respondents indicated that inadequate training was a barrier, but $85.9 \%$ perceived the need for staff to be trained. Although training alone is unlikely to solve the problem of poor compliance, it may represent an area for intervention, especially if it involves the entire theatre team.

Despite time-related issues being perceived as a major difficulty in the open-ended question, $69 \%$ of all respondents felt that the SSCL did not take too long to complete. The interpretation of this is difficult. Of all respondents, $62.5 \%$ did not believe that the SSCL was a duplication of an existing check, which was in keeping with a small proportion (3.3\%), who raised this as a factor in the openended section. This is in contrast to other studies, where both of these consistently appear as major factors. ${ }^{[16-18]}$

There was a perception by the majority of all the respondents that the SSCL was supported by nurses (62.5\%), anaesthetists (70.1\%) and management (68.5\%). This was in contrast to the perception of support by surgeons in only $45.1 \%$ of respondents. This is in keeping with other studies and suggests an area for intervention. A US study 
Table 5. Barriers to and staff perceptions of SSCL use in relation to rank of medical staff

\begin{tabular}{|c|c|c|c|c|}
\hline Responses & $\begin{array}{l}\text { Yes, } \\
n(\%)\end{array}$ & $\begin{array}{l}\text { No, } \\
n(\%)\end{array}$ & $\begin{array}{l}\text { Significance, } \\
p \text {-value }\end{array}$ & $\begin{array}{c}\text { Odds ratio } \\
(95 \% \mathrm{CI})\end{array}$ \\
\hline The checklist takes too long to complete & $35(28.9)$ & $86(71.1)$ & & \\
\hline Senior & $14(28.0)$ & $36(72.0)$ & 0.851 & \\
\hline Junior & $21(29.6)$ & $50(70.4)$ & & $0.926(0.416-2.062)$ \\
\hline It is difficult to find a co-ordinator for the checklist & $53(46.5)$ & $61(53.5)$ & & \\
\hline Senior & $21(46.7)$ & $24(53.3)$ & 0.976 & \\
\hline Junior & $32(46.4)$ & $37(53.6)$ & & $1.012(0.477-2.148)$ \\
\hline I know whose responsibility it is to initiate the checklist & $49(46.2)$ & $57(53.8)$ & & \\
\hline Senior & $25(55.6)$ & $20(44.4)$ & 0.098 & \\
\hline Junior & $24(39.3)$ & $37(60.7)$ & & $1.927(0.883-4.207)$ \\
\hline Staff needs to be trained in using the checklist & $111(87.4)$ & $16(12.6)$ & & \\
\hline Senior & $40(76.9)$ & $12(23.1)$ & 0.003 & \\
\hline Junior & $71(94.7)$ & $4(5.3)$ & & $0.188(0.057-0.621)$ \\
\hline The checklist is a duplication of an existing check & $20(19.4)$ & $83(80.6)$ & & \\
\hline Senior & $13(27.7)$ & $34(72.3)$ & 0.053 & \\
\hline Junior & $7(12.5)$ & $49(87.5)$ & & $2.676(0.967-7.405)$ \\
\hline It is unnecessary to use a surgical safety checklist & $10(7.9)$ & $116(92.1)$ & & \\
\hline Senior & $4(8.2)$ & $45(91.8)$ & 0.595 & \\
\hline Junior & $6(7.8)$ & $71(92.2)$ & & $1.052(0.281-3.934)$ \\
\hline The checklist is a waste of time & $7(5.6)$ & $119(94.4)$ & & \\
\hline Senior & $6(11.8)$ & $45(88.2)$ & 0.017 & \\
\hline Junior & $1(1.3)$ & $74(98.7)$ & & $9.867(1.150-84.635)$ \\
\hline Failing to complete the checklist is poor professional practice & $96(78.0)$ & $27(22.0)$ & & \\
\hline Senior & $35(72.9)$ & $13(27.1)$ & 0.271 & \\
\hline Junior & $61(81.3)$ & $14(18.7)$ & & $0.618(0.261-1.463)$ \\
\hline Using the checklist decreases human error & $119(94.4)$ & $7(5.6)$ & & \\
\hline Senior & $46(92.0)$ & $4(8.0)$ & 0.279 & \\
\hline Junior & $73(96.1)$ & $3(3.9)$ & & $0.473(0.101-2.208)$ \\
\hline Using the checklist improves patient safety & $116(95.1)$ & $6(4.9)$ & & \\
\hline Senior & $42(89.4)$ & $5(10.6)$ & 0.031 & \\
\hline Junior & $74(98.7)$ & $1(1.3)$ & & $0.114(0.013-1.004)$ \\
\hline Using the checklist improves teamwork in theatre & $100(82.0)$ & $22(18.0)$ & & \\
\hline Senior & $39(79.6)$ & $10(20.4)$ & 0.576 & \\
\hline Junior & $61(83.6)$ & $12(16.4)$ & & $0.767(0.303-1.945)$ \\
\hline Surgical personnel support the use of the checklist & $58(56.9)$ & $44(43.1)$ & & \\
\hline Senior & $22(55.0)$ & $18(45.0)$ & 0.760 & \\
\hline Junior & $36(58.1)$ & $26(41.9)$ & & $0.883(0.396-1.968)$ \\
\hline Anaesthetic personnel support the use of the checklist & $90(90.0)$ & $10(10.0)$ & & \\
\hline Senior & $32(88.9)$ & $4(11.1)$ & 0.517 & \\
\hline Junior & $58(90.6)$ & $6(9.4)$ & & $0.828(0.217-3.150)$ \\
\hline Nursing personnel support the use of the checklist & $71(79.8)$ & $18(20.2)$ & & \\
\hline Senior & $29(85.3)$ & $5(14.7)$ & 0.308 & \\
\hline Junior & $42(76.4)$ & $13(23.6)$ & & $1.795(0.577-5.584)$ \\
\hline Management support the use of the checklist & $81(87.1)$ & $12(12.9)$ & & \\
\hline Senior & $34(89.5)$ & $4(10.5)$ & 0.406 & \\
\hline Junior & $47(85.5)$ & $8(14.5)$ & & $1.447(0.403-5.197)$ \\
\hline I want to use the checklist & $112(91.8)$ & $10(8.2)$ & & \\
\hline Senior & $44(88.0)$ & $6(12.0)$ & 0.173 & \\
\hline Junior & $68(94.4)$ & $4(5.6)$ & & $0.431(0.115-1.616)$ \\
\hline When the checklist is used, I feel part of the team & $84(72.4)$ & $32(27.6)$ & & \\
\hline Senior & $32(69.6)$ & $14(30.4)$ & 0.578 & \\
\hline Junior & $52(74.3)$ & $18(25.7)$ & & $0.791(0.347-1.807)$ \\
\hline
\end{tabular}

showed that nurses and anaesthetists felt that surgeons participated effectively in the time-out process ( $47 \%$ and $58.3 \%$, respectively), but surgeons felt that they participated effectively in $96 \%$ of cases. ${ }^{[19]}$
The study postulated that this was due to poor communication. Fourcade et al. ${ }^{[16]}$ also described poor communication between surgeons and other theatre personnel. 
In comparison to anaesthetists, surgeons were 3.1 times less likely to find it difficult to locate a co-ordinator (Table 4). Compared with nurses, anaesthetists were 4.4 times more likely to not know whose responsibility it was to initiate the SSCL, and 5.5 times more likely to think that it was necessary to use the SSCL. With regard to support of the SSCL, anaesthetists were consistently more likely to feel that surgeons, nurses and management did not support use of the checklist. These differences between the groups may point to a need for differential interventions for each in some respects.

Compared with junior staff, senior staff were 5-fold more likely to feel that staff did not need to be trained, and 8-fold more likely to indicate that the checklist did not improve patient safety (Table 5). Junior staff were 9.8 times more likely to feel that the checklist was not a waste of time, although the $95 \% \mathrm{CI}$ for this is very wide. The difference in opinion between senior and junior staff is therefore quite stark, and may well reflect a generational difference in exposure to safety practices such as the SSCL.

\section{Study limitations}

The study is subject to a few limitations. The convenience sampling using two hospitals only may mean that the sample may not be representative of the population in the area. The barriers identified in this study may also be specific to these centres and therefore not generalisable. As this was a questionnaire-based study with answer options provided for some questions, it may not be a true reflection of current practice. We did not investigate compliance with the SSCL, making an assumption that its use was not optimal.

Exploring the apparent relative success of the implementation of the SSCL among private hospital groups in SA may help to clarify the difference in barriers in the public and private settings. Factors such as different training and implementation strategies, stricter adherence to hospital policies and the perception of the SSCL as a cost-saving intervention may be postulated as factors driving the use of the SSCL in the private sector.

\section{Recommendations}

We propose some recommendations similar to those of Vats et al. ${ }^{[17]}$ to facilitate the use of the WHO SSCL in our context. There needs to be widespread training in the use of the SSCL, including adaptation of the checklist to make it fit for purpose in the setting. There needs to be a focus on enhancing the functioning of the various role players in the operating theatre as a team, with a particular emphasis on including the surgeons. Local champions need to be cultivated and there has to be regular audit and feedback to evaluate the checklist use and identify new issues that may arise.

\section{Conclusion}

The WHO SSCL is an important tool in the operating theatre environment. It improves patient safety, enhances communication and fosters teamwork. The barriers in our setting are similar to those identified in other settings and improving compliance should therefore focus on these. Improving effective and widespread use of the checklist will allow theatre staff to work together towards ensuring a safer theatre environment for both patient and staff.

Acknowledgements. The authors would like to thank all the respondents for participating in the study, and Dr Kim de Vasconcellos for his assistance with the data analysis.

Author contributions. SV collected the data, analysed the data, wrote the article and approved the final version. PDG supervised the study conduct and data collection, analysed the data, wrote the article and approved the final version.

Funding. None.

Conflicts of interest. None.

1. Weiser TG, Regenbogen SE, Thompson KD, et al. An estimation of the global volume of surgery: A modelling strategy based on available data. Lancet 2008;372(9633):139-144. https://doi. org/10.1016/s0140-6736(08)60878-8

2. Kable AK, Gibberd RW, Spigelman AD. Adverse events in surgical patients in Australia. Int J Qual Health Care 2002;14(4):269-276. https://doi.org/10.1093/intqhc/14.4.269

The International Surgical Outcomes Study Group. Global patient outcomes after elective surgery: Prospective cohort study in 27 low-, middle- and high-income countries. Br J Anaesth 2016:117(5):601609. https://doi.org/10.1093/bja/aew316

4. Pearse RM, Moreno RP, Bauer P, et al. Mortality after surgery in Europe: A 7-day cohort study. Lancet 2012;380(9847):1059-1065. https://doi.org/10.1016/s0140-6736(12)61148-9

5. Biccard BM, Madiba TE; on behalf of the South African Surgical Outcomes Study Investigators. The 5. Biccard BM, Madiba TE; on behalf of the South African Surgical Outcomes Study Investigators. The
South African Surgical Outcomes Study: A 7-day prospective observational cohort study. S Afr Med J South African Surgical Outcomes Study: A 7-day prospec 2015;105(6):465-475. https://doi.org/10.7196/samj.94

6. World Health Organization. WHO guidelines for safe surgery 2009. Safe surgery saves lives. http:// whqlibdoc. who.int/publications/2009/9789241598552_eng.pdf (accessed 26 February 2018).

7. Haynes AB, Weiser TG, Berry WR, et al. A surgical safety checklist to reduce morbidity and mortality in a global population. N Engl J Med 2009;360(5):491-499. https://doi.org/10.1016/j.spinee.2010.04.021

8. Takala RSK, Pauniaho S-L, Kotkansalo A, et al. A pilot study of the implementation of WHO surgical checklist in Finland: Improvements in activities and communication. Acta Anaesthesiol Scand 2011;55(10):1206-1214. https://doi.org/10.1111/j.1399-6576.20111.02525.x

9. Urbach DR, Govindarajan A, Saskin R, Wilton AS, Baxter NN. Introduction of surgical safety checklists in Ontario, Canada. N Engl J Med 2014;370(11):1029-1038. https://doi.org/10.1056/NEJMsa1308261

10. Lübbeke A, Hovaguimian $\mathrm{F}$ Wickboldt $\mathrm{N}$, et al. Effectiveness of the surgical safety checklist in a high standard care environment. Med Care 2013;51(5):425-429. https://doi.org/10.1097/ mlr.0b013e31828d1489

11. Naidoo M, Moodley J, Gathiram P, Sartorius B. The impact of a modified World Health Organization surgical safety checklist on maternal outcomes in a South African setting: A stratified clusterrandomised controlled trial. S Afr Med J 2017;107(3):248-257. https://doi:10.7196/samj.2017.v107i3.11320

12. Giles K, Munn Z, Aromataris E, et al. Use of surgical safety checklists in Australian operating theatres: An observational study. ANZ J Surg 2017;87(12):971-975. https://doi.org/10.1111/ans/13638

13. Levy SM, Senter CE, Hawkins RB, et al. Implementing a surgical checklist: More than checking a box. Surgery 2012;152(3):331-336. https://doi.org/10.1016/j.surg.2012.05.034

14. Anwer M, Manzoor S, Muneer N, Qureshi S. Compliance and effectiveness of WHO surgical safety check list: A JPMC audit. Pak L Med Sci 2016;32(4):831-835. https://doi.org/10.12669/pjms.324.9884

15. Bashford T, Reshamwalla S, McAuley J, Allen NH, McNatt Z, Gebremedhen YD. Implementation of the WHO surgical safety checklist in an Ethiopian referral hospital. Patient Safe Surg 2014;8(1):16, https://doi.org/10.1186/1754-9493-8-16

16. Fourcade A, Blache J-L, Grenier C, Bourgain J-L, Minvielle E. Barriers to staff adoption of a surgical safety checklist. BMJ Qual Saf 2011;21(3):191-197. https://doi.org/10.1136/bmjqs-2011-000094

17. Vats A, Vincent CA, Nagpal K, Davies RW, Darzi A, Moorthy K. Practical challenges of introducing WHO surgical checklist: UK pilot experience. BMJ 2010;340:b5433. https://doi.org/10.1136/bmj.
Wh b5433

18. Treadwell JR, Lucas S,Tsou AY. Surgical checklists: A systematic review of impacts and implementation. BMJ Qual Saf 2012;23(4):299-318. https://doi.org/10.1136/bmjqs-2012-001797

19. Papacontsantinou HT, Jo C, Reznik SI, Smythe WR, Wehbe-Janek H. Implementation of a surgical safety checklist: Impact on surgical team perspectives. Ochsner J 2013;13(3):299-309.

Accepted 30 October 2017. 